\title{
THE POTATO LEAFHOPPER AND ITS RELATION TO THE HOPPERBURN
}

\author{
By E. D. Batr, Ames, Iowa
}

The leaves of the potatoes were badly burned during the season of 1918 all over the whole northern part of the United States, from Montana to New York, and New Jersey south to Kansas and Ohio. In different places it was called "blight, tipburn, or aphis work." The writer's attention was called to it on July 17 . At this time the early potatoes in southern Wisconsin were largely dying or dead from the trouble. On examining the injured plants it was found that the leaves with only the margins burned invariably had nymphs or cast skins of the potato leafhopper (Empoasca mali LeB.) on the under sides. Upon investigation, it was found that even the leaves that had been burned entirely brown still had the cast skins of the leafhoppers in numbers, showing conclusively, that the insects had been present on them for some time. Egg scars were also found on all burned leaves at this time. Oftentimes it was possible to find a leaf with a single egg scar, the five cast skins of the different stages of the nymph and the freshly hatched leafhopper, showing that the whole life up to that date had been passed upon the single leaf. The uninjured leaves were also examined, but no egg scars, cast skins, or nymphs were found on them. The adults were just beginning to fly and occasionally a fresh adult, apparently a new arrival, would be found on an uninjured leaf.

\section{Description OF the InJURy (Hopperburn)}

The injury varies somewhat with different varieties and different conditions of temperature and moisture, but in general, the first sign is a triangular burned area at the top of the leaf, followed by progressive appearance of burned areas, more or less triangular, along the margin. These areas coalesce as the burning progresses, until the entire margin of the leaf is brown and more or less curled up. The burned margin increases in width, until only a narrow strip along the midrib remains. In the worst cases, this strip and the midrib burn, the leaf dies, and later the plant succumbs, standing burned and dry.

On examining carefully the burned leaves, egg scars will be found in the midribs and leaf stems, as shown in 2,3 , and 4 of figure 7 . Often the burned triangle at the tip will be found to extend back nearly to a place where one or more egg scars have so distorted the midrib that it has collapsed beyond that point. The burned areas along the margin will often be found to extend in some distance on the lateral 
veinlets and these veinlets will appear collapsed and brown, to a point where there appears to be a series of punctures probably made by the beaks of the nymphs.

The more rapid growing varieties of potatoes suffered less than those of slower growth, apparently due to the larger number of leaves produced. Each leafhopper appeared to be able to destroy a leaf. If there were only as many hoppers as leaves, the plant kept on growing; if on the other hand, there were two hoppers to a leaf, it died.

\section{The Relation of Hopperburn to Tipburn}

Tipburn has been used for years, to designate any burned condition of the leaves, for which no causal agent could be found, the most common explanation being that it resulted from too rapid transpiration due to abnormal conditions of temperature and moisture, although Dr. L. R. Jones, in first discussing it, suggested that insects might be a factor in its production. It seems probable that a considerable amount of the injury referred to as tipburn, in the past, has been due to the leafhopper. On the other hand, there are, no doubt, other causes of the burning of potato foliage and it will be one of the problems of the future to differentiate these factors.

At first it was thought that there was a great variation in susceptibility of different varieties, but further study appeared to show that the variation was due to the difference in time that the foliage appeared on the potatoes.

Potatoes that were up at the time that adult leafhoppers were flying in the spring, were injured in about the proportion of their foliage. Potatoes that came up later, even if in adjoining rows, were not injured at all until the adults of the new generation flew to them in July and August.

In every case the first injury appeared on the older leaves, below the top. This was due to the fact that between the time the eggs were laid and the young nymphs had hatched and had time to produce the injury, new leaves would have grown above the injured ones.

\section{Cage Experiments}

A cage was put over a medium-sized potato, early in August, and between 200 and 300 leafhoppers added. In three days all of the upper leaves of the plant were rolled up and burned brown and the growth of the plant stopped. Following this, two cages were placed over potato plants of equal size. Another plant of similar size was selected as a field check. These plants were scarcely two-thirds of the height of the cages and were considerably burned on the lower half when caged.

In one cage, between 200 and 300 leafhoppers swept from the field 
were placed. The leafhoppers on the other plants were carefully removed before the cage was put on. The third plant remained under field conditions and during the next three weeks of hot, dry weather, the burning developed upon the upper part of the plant in considerable amounts, so that the whole field showed a brown cast, where before it had looked green.

At the end of three weeks the cages were removed and the three plants examined, after which their tops were cut off and photographed and then preserved.

The plant on which the hoppers were placed (Pl. 5, fig. 1) had evidently died within a short time, then the leafhoppers died and later, two green shoots came up from the stem near the base. These were green and not burned, while the former top was curled up brown and dead. The check plant had grown but little in height and the burning had progressed clear to the top (P1. 5, fig. 2). The plant from which the leafhoppers had been removed, had grown rapidly and filled the top of the cage. The leaves were broad, smooth and bright green, with long, acute tips and without a trace of browning (Pl. 5, fig. 3).

\section{Is the Hopperburn Specific?}

The closely related leafhoppers working on rose, apple, grapes and woodbine, produce a whitened appearance on the upper side of the leaves, due to innumerable minute white spots that are apparently the result of feeding punctures. These feeding punctures are practically all made from the under side of the leaves, where the nymphs are found. In no case, however, is there any marginal burning of the leaves, or any browning, until the leaves are so badly injured that they are practically dead.

In the case of the potato leafhopper, the effect is quite different. The burning occurs while the other parts of the leaf are apparently uninjured and the margin of the burned area is always sharp and definite. This leafhopper attacks dahlias and produces the same marginal burning, as well as the same egg scars and distortion of the midribs and veinlets as on potatoes. It is also found attacking water sprouts and fast-growing tips of box elder trees and producing the same type of burning. Water sprouts and fast-growing shoots of nursery stock, and apples are also attacked, the leaves curled and the tips burned. The upper leaves on fast growing raspberry canes are similarly curled and burned.

All the evidence at hand indicates that the hopperburn is produced in every case by this one insect and by this one only. Whether or not it will prove to be a specific disease like the curly-leaf, transmitted by 
the beet leafhopper, is yet to be worked out, but in any case, its relation to the potato leafhopper seems to be a specific one.

\section{Life-History of the Leafhopper on Potatoes}

The life-history of this species has been studied mainly in connection with its work as a nursery pest and reported under the name of the apple leafhopper. ${ }^{1}$ Washburn, Webster and others have reported it as having from four to six generations per year. In practically all of this work the three species of leafhoppers commonly found on apples have apparently been confused.

Parrott was the first to clear this matter up and Lathrop, ${ }^{2}$ working at Geneva, first differentiated the life-histories of the three species. He showed that the rose leafhopper (Empoa ros(e) wintered as an egg, mainly on roses, produced two generations, the second one on apples; that Empoasca unicolor Gill, the true apple leafhopper, spent its whole life on apples, wintering as an egg under the bark and producing a single generation a year; while Empoasca mali LeB., hereafter to be called the potato leafhopper, wintered as an adult and produced two broods during the season.

The writer's observations during 1918 indicated that two generations were produced on potatoes. The adults flying in the spring at the time the early potatoes come up, laid their eggs in the stems and midribs of the leaves (fig. $7,2,3,4$.) These hatched into nymphs (fig. $7,1 \mathrm{c}$ ) that fed on the under sides of the leaves, remaining on the single leaf, as shown by the successive cast skins, unless disturbed or, in case there were several on the leaf, until it died when they would migrate to another. During July and early August the first generation changed to adults and deposited eggs again or flew to the late potatoes to start the second generation there.

\section{Proof That the Leafhopper Caused the Hopperburn}

That the burned condition of the potato leaves observed in 1918 was due to the attack of the leafhopper seems to the writer to be well established by the following summary of proof:

First: Cage experiments showed that the leafhoppers could burn and roll the leaves in three days and that plants from which leafhoppers were all removed grew rapidly without sign of hopperburn.

Second: All burned leaves showed on their under surface, either the leafhoppers, their cast skins or egg scars; often all three, while green leaves showed no traces of these. Injury was proportional to the number of leafhoppers.

\footnotetext{
${ }^{1} \mathrm{~A}$ more extended discussion together with a complete bibliography will be found in the "Second Biennial Report of the State Entomologist of Wisconsin, 1919."

2 Jodrnal of Economic Entomology, Vol. II, p. 144, February, 1918.
} 

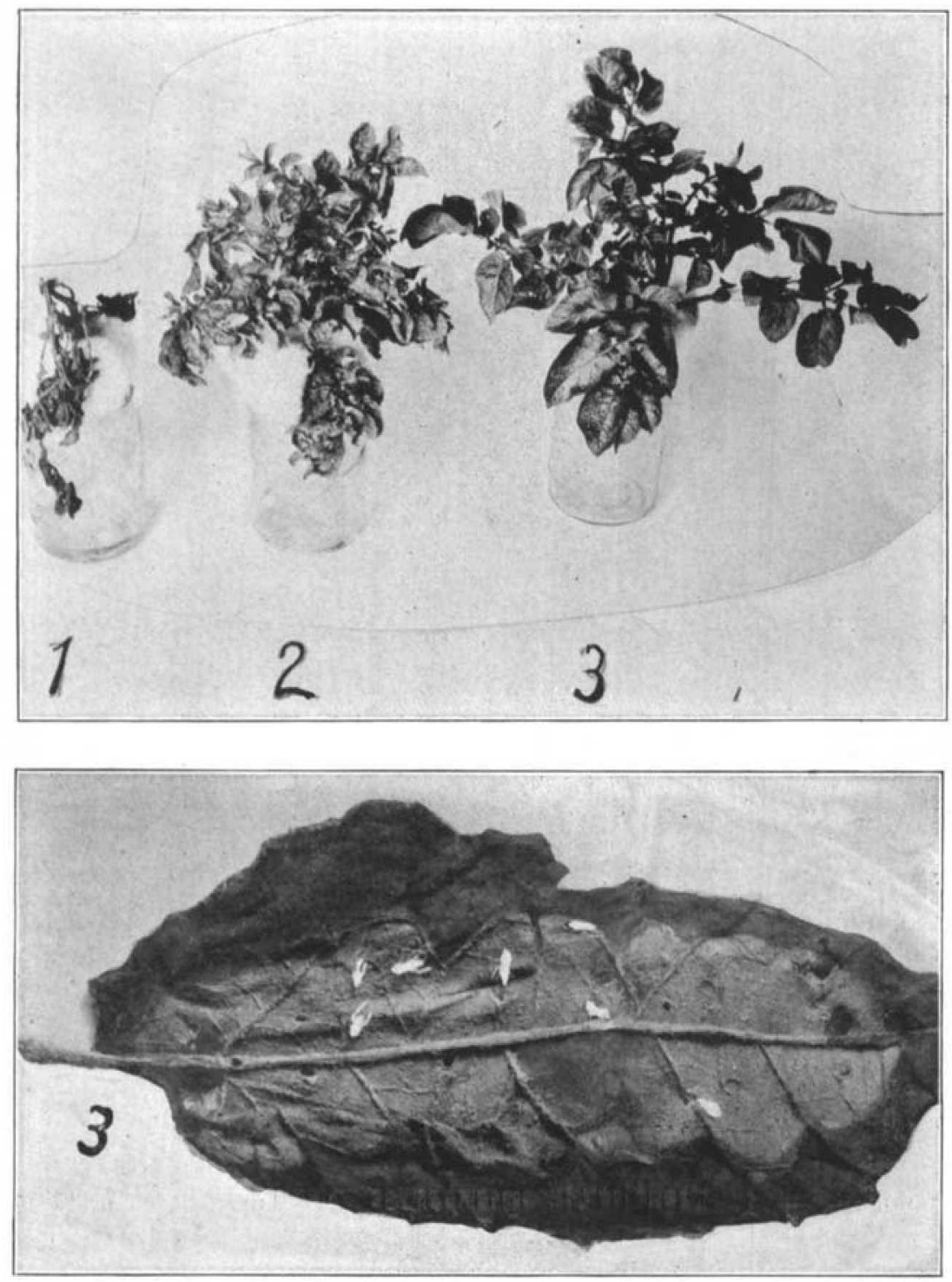

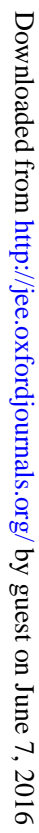

1. Top of potato plant from cage in which leafhoppers were placed; 2 . Top of check plant from field; 3 . Top of plant from which all hoppers were removed; 3. (Lower electro.) Potato leaf showing hopperburn and the cast skins of the leafhoppers producing it. 


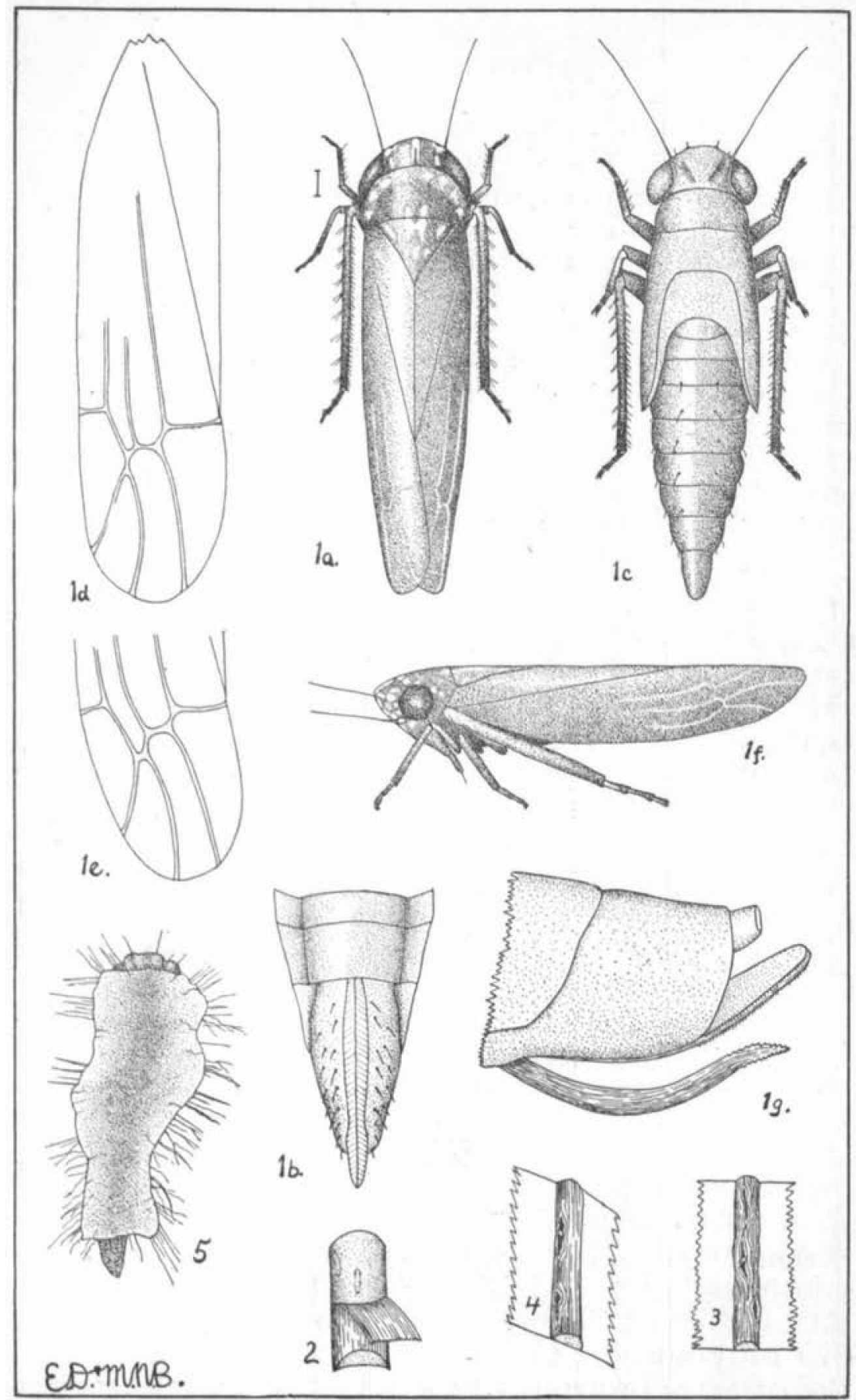

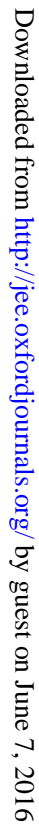

Fig. 7. The Potato Leafhopper; $1, a$ and $f$, the leafhopper; $c$, nymph; $d$ and $e$, venation of elytron; $g$, "saw-like" ovipositor with which the eggs are thrust into the stems; 2 , eggs in the stem; 3 and 4, egg scars in midrib; 5 , nymph killed by fungus. 
Third: Burning always appeared on the older leaves below the top of the growing plant, showing that time must elapse before its appearance (time for eggs to hatch).

Fourth: Burning on plants had no relation to position with reference to exposure, to sun or to soil.

Fifth: Burning in fields had no reference to soil condition, slope or exposure.

Sixth: Different varieties were affected according to the time they came up, or according to amount of foliage present when the leafhoppers were laying eggs.

Seventh: Epidemics of leafhoppers and hopperburn (called tipburn) have been observed at the same time, on a number of previous occasions.

Eighth: Other plants attacked by the potato leafhopper show the same distinct types of marginal burning: dahlia, box elder, apple and raspberry:

\section{Control}

Spraying with a rather strong kerosene emulsion or with Black Leaf 40 , one pint to one hundred gallons of water, to which five pounds of soap have been added, was found effective in killing both nymphs and adults. The sprays must be applied from below, by means of a shepherd's crook made from $\frac{1}{2}$-inch gas pipe, or applied from above while the plants are drawn over by a suspended board. Two sprayings, a week or ten days apart, applied from opposite directions, were sufficient to control.

Vice-President W. C. O'Kane: Is there any discussion of this paper?

Mr. P. J. Parnotr: Is this the same trouble that the plant pathologists call tipburn?

President E. D. Ball: I am with the plant pathologists in saying that there is no question but what some of the things they called tipburn in the past were not this, but a large part of it was this.

Mr. P. J. Parrott: Mali winters as an adult?

President E. D. Ball: Yes.

Mr. P. J. Parrotr: What are its earlier food plants before it goes over to the potato?

President E. D. Ball: Mali goes over to a very large variety of plants.

Mr. E. P. FelT: Do I understand that this injury in the opinion of Dr. Ball is largely mechanical?

President E. D. Ball: I doubt it; I am inclined to believe that it is specifical, an infection or an injection. 
Mr. MCCAMpbell: When you advise the farmers to spray, how far apart would the sprays be?

President E. D. Ball: A week or ten days apart.

Mr. C. P. Gillette: Are the eggs laid wholly on the veins?

President E. D. Ball: On the midribs and the stalks of the leaves. As soon as they have destroyed the leaves they will feed on the stems and destroy them also. But they feed on the leaves apparently up to the time that the leaves die.

Mr. H. A. Gossard: We had in Ohio the maple injured similarly to tipburn and from the association of this species, we attributed it to that.

President E. D. Ball: This is the leafhopper that injures the growing shoots of nursery stock and young apple trees and burns them; it is the leafhopper that injures the growing tips of raspberry canes; it is not the leafhopper that injures the leaves of apple trees; it is almost never found on a slow-growing apple tree. On box-elder, it is only found on the water shoots or the fast-growing tips.

Mr. P. J. PARrotT: In Geneva we have a great deal of trouble on the nursery maples.

Mr. J. T. HEA DLEE: Can the speaker give us some idea of how much an infestation is necessary to bring about the results on potatoes that he describes?

President E. D. Ball: One leafhopper will destroy a leaf.

President E. D. Ball: The next paper on the program will be by Mr. O'Kane on "Limitations in Insect Suppression."

\title{
LIMITATIONS IN INSECT SUPPRESSION
}

\author{
By W. C. O'KANE
}

At the outset there should be some further definition of the subject of this paper. What I have in mind is a brief discussion of some of of the difficulties and problems that arise when the entomologist faces the task of organizing a campaign against a new and serious insect outbreak. Necessarily these difficulties and problems will vary widely with the insect, the part of the country invaded, the host plant and other factors, including the entomologist himself. Therefore that which follows can be only the view of one entomologist, based on an experience necessarily limited and on contact with only relatively few serious insects. That which constitutes a difficulty in New England may turn out differently elsewhere, with another type of citizen to deal with and with another man to do the dealing.

However, no matter where the work or who the worker, there is at 